\title{
Mechanisms of activation of maternal behaviour in mammals
}

\author{
Pascal POINDRON* \\ UMR 6175, CNRS-INRA - Université de Tours - Haras Nationaux, Physiologie de la Reproduction \\ et des Comportements, 37380 Nouzilly, France
}

\begin{abstract}
In mammals, the activation of maternal behaviour depends on internal maternal factors related with parturition. The nature of these factors may vary between species, although oestradiol, foetus expulsion and intracerebral oxytocin are the most commonly encountered. They induce a period of specific receptivity to some sensory cues provided by the neonate. These cues (tactile, olfactory, auditory, ...) also vary between species. The interactions between the mother and her progeny during this period, known as the sensitive period, facilitate the maintenance of maternal responsiveness beyond the initial phase of activation by the factors internal to the mother. The ability of mothers to display a well-adapted maternal behaviour is also modulated by maternal experience gained at the first parturition. Furthermore, this capacity is also influenced by the nature of the interactions experienced in infancy with the own mother of the female, which can lead to a nongenomic transmission of some individual characteristics of maternal behaviour or sensitivity to stress across generations.
\end{abstract}

maternal behaviour / physiological control / mammals / maternal experience

\section{INTRODUCTION}

The breeding success of an animal can be defined by its aptitude to transmit its genes to the following generation of a population, the most often via the animal's direct descendants. In mammals, even though fertilisation is the first vital step, the capacity to raise young is also a critical element in this process. Indeed, the presence of welladapted maternal behaviour at parturition is essential for the survival of the newborn, with the mother being the only source of food for several days or weeks. The care that the female has for her progeny will consequently condition as much as fertilisation the success of the breeding parents, even if it is in general the mother that raises her young, except in a few species for which both parents care for the young (biparental care [1]).

In this review, we are going to concentrate on the most general case, which is that of the care given by the mother, which is obligatory, since the father cannot meet the nutritional needs of the young at the beginning of its life. The care that the mother gives to her young is also important for the physiological and psychological development of the young. Beyond just the survival of the young, the quality of maternal care will influence the development of the

\footnotetext{
* Corresponding author: poindron@ @ours.inra.fr
} 
young physiologically or psychologically, not only on the short term [2], but also on the middle and long term. The mother-progeny interactions represent the first social experience of the young and can thus influence the preferences of the adult age. This has been shown in particular for food preferences, but also for the choice of a sexual partner [3,4]. This importance of maternal behaviour has several implications, notably concerning the nature of the care given to the young and the mechanisms of activation of maternal motivation.

\section{THE NATURE OF CARE GIVEN TO THE YOUNG}

All young are not born with the same degree of maturity, whether this concerns motor or sensory development or their thermoregulation. Consequently, the behaviour of the mother, which should be perfectly adapted to the need of each type of newborn, will be different depending on the degree of development of the young at birth. A mother cannot have the same behaviour when a young is born with a low level of development (altricial young) and when the young has a high degree of maturation at birth (precocial young). In the category of altricial young figure marsupials, rabbits, rats, mice and many other rodents, and in that of precocial young, the ungulates, guinea pig or pinnipeds. In primates, the situation is intermediate: the mobility of the newborn is relatively low, although it is a little superior than in altricial animals. However, their sensory development is much higher. Altricial young are generally deaf and blind at birth whereas primates often have a visual and auditory perception that is much more developed. Consequently, the care given by mothers will be different. In young altricial species, the behaviour of the mother is focussed and structured depending on the existence of a marsupial pouch or a nest. For example, characteristic behaviour of mothers building a nest is to retreive all young that have strayed away. Nursing also occurs within the nest. In addition, the relationship is often non exclusive; that is the mother gives care (licking, nursing) to all young that are inside the nest, even if they belong to another mother [5]. However, after the young have left the nest, the female may show selective maternal behaviour [6].

In primates, the relationship is characterised essentially by the mother carrying the young. In humans, this transportation often occurs in a baby carriage in occidental societies, although the harness is becoming more frequent, becoming closer to the way of transport observed in some more traditional societies, with fabric attached to a shoulder strap that allows the infant to be carried on the stomach or back. In nonhuman primates, the young is either carried in the arms or attaches itself to the coat of the mother (clinging behaviour); this type of relationship is known as matricolia [7]. Finally, in species giving birth to precocial young, the mother does not usually build a nest, but develops an exclusive relationship with her young. After parturition, the female learns within several hours or even less in some cases, to recognise her young. She only takes care of hers, rejecting any other young that tries to nurse. This selective mother-progeny relationship is particularly well documented in the sheep and goat. An exception to the rule is the maternal behaviour of the sow, even though the newborn has one of the highest motor and sensory developments. Despite this, the mother builds a nest and the young stay there for about one week; the maternal behaviour is little selective [8]. This is probably due to the high number of piglets in the litter, and since the young have a poor thermoregulation during the first week of their life. It is also important to underline that a non-exclusive relationship does not necessarily mean the absence of recognition. In all of these species, whether the mothers show a selective maternal behaviour or not, they are capable of recognising their young. In some species in which mothers recognize their young, alien offspring are also 
accepted, whereas in other species, mothers recognize and only accept their own young.

\section{THE ACTIVATION OF MATERNAL MOTIVATION}

Besides the fact that maternal behaviour should be adapted in an optimal manner to the needs of the newborn, the mother must be able to show this behaviour at birth, whether the young is precocial or altricial. In other words, her maternal motivation should be maximal at the birth of her young. For this, two extreme solutions can be foreseen. One possibility is that the mother be able to very rapidly and permanently express a maternal behaviour as soon as she is in the presence of a newborn, even with females that have never before had a maternal experience. This is the case for example with mice, and in this case, the activation of the maternal behaviour is mainly under sensory control [9]. The other solution is, on the contrary, that the activation of maternal motivation be completely controlled by the physiological events that accompany parturition. This second type of control is that which can be found in the ewe. In this species, whatever the degree of maternal experience of the mother, physiological factors remain necessary to help obtain an immediate onset of maternal behaviour. Between these two extreme cases, there are intermediary solutions, as in the rat. In a female rat that has never given birth, the physiological factors are extremely important, since a virgin female who has never raised young can take one week or more to show maternal care when she is exposed in a continuous manner to young (sensitisation process). However, a few hours of interaction just after parturition are sufficient for a first time mother to acquire a maternal experience that will allow her to free herself from physiological factors. Thereafter, she will then be able to display maternal behaviour with a much shorter latency ( $24 \mathrm{~h}$ or less) whatever her physiological state and even if she is not pregnant [10].

\section{THE EXISTENCE OF A SENSITIVE PERIOD}

Whether it concerns an essentially sensory or physiological control, in all cases studied up to the present, parturition always represents a privileged period for the expression of maternal behaviour by the female and the development of a relationship with progeny [11]. This indicates that the physiological events associated with parturition play a specific role at this moment. This is true even in mice, despite the apparently independent maternal behaviour towards physiological factors in this species. Indeed, in the mouse, there is a high level of motivation; nevertheless, the physiological factors will reinforce the receptivity of the mother to specific cues from the pups. This is true too in humans where we have a few indications that some factors associated with gestation or birth can facilitate the receptivity of certain sensory information from the newborn $[12,13]$.

\section{THE ACTIVATION OF MATERNAL BEHAVIOUR IN THE EWE}

In the ewe, two main factors act in synergy to permit the manifestation of maternal behaviour. These are oestradiol and the cervico-vaginal simulation caused by delivery. The secretion of oestradiol by the placenta is increased in the female at the end of gestation, culminating with an acute peak in the last $24 \mathrm{~h}$ preceding the birth of the lamb. The delivery of the foetus induces the peripheral secretion of oxytocin which reinforces the contractions, as well as releasing of this hormone in the brain, which stimulates maternal behaviour. These two factors taken separately are little efficient, as induction experiments of maternal behaviour in non-pregnant ewes have shown $[14,15]$. However, their synergetic action allows the immediate expression of complete maternal behaviour. The secretion of oestradiol in the days preceding parturition prepares the nervous system to be able to respond in an 
optimal manner to the cervico-vaginal stimulation, by stimulating the intracerebral synthesis of oxytocin and its receptors. At this time it is not totally clear wether the strong peak of oestradiol that occurs at birth plays a very important role in the expression of maternal behaviour at parturition. In fact, recent results in the ewe indicate that at parturition, the expression of oestrogen receptors in the cerebral structures implicated in the activation of maternal behaviour is rather low (medial preoptic area, paraventricular nucleus of the hypothalamus, amygdala [16]).

Besides these two key factors, some other peripheral and central physiological parameters also participate in the activation of maternal behaviour at parturition, even though their role may not be as determinant. For example, the decrease in the peripheral concentration of progesterone facilitates the effects of cervico-vaginal stimulation [14]. This is also the case for the central release of opiates, and also maybe for $\mathrm{CRH}$, although for this latter factor, its intracerebral releasing at the moment of parturition has not yet been shown in the ewe (unpublished results). The bringing into play of these different factors and probably others that have not yet been studied, result in a rapid increase of maternal motivation in the 3 or $4 \mathrm{~h}$ preceding parturition, culminating at delivery. Then, maintaining this motivation will depend on the possibility of the mother to interact with the newborn. If the ewe is not allowed to have contact with her newborn at birth, the maternal motivation decreases very rapidly: $24 \mathrm{~h}$ after parturition, more than three-quarters of the mothers are no longer capable of displaying maternal behaviour when they are put together again with their young [17, 18]. This is a sensitive period because, if this separation does not occur at parturition but $24 \mathrm{~h}$ later, most mothers are capable of accepting their lamb if it is returned to them. Therefore, the experience that the mother acquires by interacting with the newborn during the first hours is essential, allowing the "consolidation" of maternal motivation.
However, one must remember that if the length of separation is increased (for example by 36 or $48 \mathrm{~h}$ ), one will observe a loss of maternal behaviour, even in ewes having interacted with their young for the first $24 \mathrm{~h}$ [19]. In other words, the contact with the young is also important to maintain maternal behaviour during lactation. Indeed, even if the length of the separation that the mother can stand without hindering her capacity to care for her young increases as a function of the time of earlier contact, this separation cannot exceed a few days.

\section{THE ACTIVATION OF MATERNAL BEHAVIOUR IN OTHER MAMMALS}

The physiological mechanisms of activation of maternal behaviour are well known in the female rat; an important number of studies have been performed since the 1960s [20]. Certain similarities exist with the mechanisms found in the ewe. There, the decrease of progesterone facilitates the action of other factors. Oestradiol is generally considered to play a predominant role since in nulliparous females, the administration of this steroid is sufficient to induce maternal behaviour with a latency of less than $24 \mathrm{~h}$ (against 7 days in controls). However, one can remark that the criteria of induction used are generally less strict than in ewes, where 2-h latencies are considered abnormal. If, in the female rat, one systematically considers such demanding criteria, maybe one would find that oestradiol only is not sufficient to induce behaviour as efficiently as parturition.

In fact, numerous studies have shown that many factors act in a converging way. The studies by Bridges and his collaborators in the rat, underline the role of prolactin, which stimulates maternal behaviour, but only after impregnation by oestrogens [21]. Prolactin has also been shown to play an important role in the rabbit $[1,22]$. Concerning cervico-vaginal stimulation, to our knowledge, only one study has shown its 
Table I. Summary of the main factors involved in the control of maternal behaviour at parturition in mammals.

\begin{tabular}{|c|c|c|c|c|c|c|c|c|c|c|}
\hline & \multirow[t]{2}{*}{ Rat } & \multirow[t]{2}{*}{ Mice } & \multirow[t]{2}{*}{ Rabbit } & \multirow[t]{2}{*}{ Vole } & \multirow[t]{2}{*}{ Opossum } & \multirow[t]{2}{*}{ Ewe } & \multirow[t]{2}{*}{ Goat } & \multirow[t]{2}{*}{ Sows } & \multicolumn{2}{|c|}{ Primates } \\
\hline & & & & & & & & & Non human & Human \\
\hline Estradiol & + & $t^{*}$ & & & & + & & & + & \\
\hline Progestérone & - & $+*$ & & & & 0 & & & & \\
\hline SCV & + & & & & & + & + & & $+?$ & \\
\hline Ocytocine & + & + & & + & $+* *$ & + & & & & \\
\hline Opiacés & - & & & & & + & & & & \\
\hline Prolactin & + & + & & & & 0 & & + & & \\
\hline $\mathrm{CRH}$ & & & & & & + & & & & \\
\hline $\mathrm{CCK}$ & & & & & & & & & & \\
\hline Prostaglandins & + & & & & + & & & + & & \\
\hline Corticostériods & & & & & & & & & & + \\
\hline
\end{tabular}

* Action needing the presence of the two hormones. ** Active in peripheral injection. 0 Without known role according to the existing literature.

facilitating role [23]. However, these results are without doubt very significant, especially since this study is one of the few studies where the reported induction latencies are very short (around $30 \mathrm{~min}$ ), being compatible with the survival of the young. These results are also valuable considering the role of intracerebral oxytocin in the activation of maternal behaviour in this species. In fact, it is in the female rat that its action was first shown. At first controversial, the role of this neuropeptide is now well known, even if its effect may be more or less important depending on the strain of rats used.

CCK can also facilitate the display of maternal behaviour, since it helps oxytocin secretion. Even though they are present in high concentrations at parturition, opiates are generally considered as having an inhibiting role in the rat [24]. However, that may depend in part on the experimental conditions and the way they are applied, since there are reports of a facilitating effect of opiates on maternal behaviour [25]. Finally, prostaglandins, which play a role in the triggering of parturition, can also facilitate the appearance of maternal behaviour in pseudo-gestating rats as well as in the sow [1], even if the exact level at which it acts remains to be identified.
The combined effect of these different factors is similar to that reported in the ewe, resulting in the existence of a sensitive period of receptivity to newborns. The maternal behaviour appears in the three hours preceding birth, with a maximal acceptation rate at parturition, followed by a progressive decrease of motivation. However, in female rats deprived of any contact with their progeny from the very time of parturition, it takes about 7 days for maternal motivation to return its base level. Therefore, activation by physiological factors lasts longer than in the ewe. However, as in the ewe, 30 min of interaction with newborns in the female rat is enough to maintain maternal behaviour for at lest 10 days. The importance of these first interactions just after parturition has also been shown in the rabbit [26] and can be more or less clearly found in all the species studied.

A summary of the main factors implicated in the control of maternal behaviour at parturition in mammals is presented in Table I $[1,27]$. It can be seen that many factors have not yet been studied in several species, and there is a lot of information that we do not yet know. Most of the knowledge we have is for the rat, mouse and ewe. In almost all species that have been studied 
today, oestradiol plays a facilitating role, including in non-human primates [28-30]. This is also true in the mouse, although in this species oestradiol must act synergistically with progesterone. In other species, progesterone is either inhibitory or has no clear action. Cervico-vaginal stimulation is very important in all species where its role has been looked for, as is the intra-cerebral release of oxytocin, which can even act in the periphery in marsupials. Prolactin is implicated in several species; its role has been shown in the rat and rabbit [21, 23]. Several data suggest a role of prostaglandins, in particular in the pig. In humans, cortisol seems to be associated with higher maternal affectivity state in the mother, in particular for elements of the newborn such as his/her cry or odour [31,32].

\section{SENSORY INFORMATION IMPLICATED INTHE ACTIVATION OF MATERNAL BEHAVIOUR}

The sensitive period represents a phase during which the control of maternal behaviour changes from endocrine/neuroendocrine to neurosensory [5]. This is therefore a phase of specific receptivity, towards pertinent sensory information coming from the newborn, to which the mother is more sensitive due to the influence of internal factors. The nature of these sensory cues is not necessarily the same for all species, since the nature of the mother-progeny relationship varies with the degree of maturity of the young at birth. In the mouse, the mother reacts better to ultrasounds of $50 \mathrm{kHz}$ frequencies, which are those emitted by the newborn, than does a non-pregnant female, and this sensitivity is under the influence of oestrogens. In the female rat, we know that physiological factors mainly act on perception and the treatment of tactile signals around the snout and on the abdomen. They also act on the perception and/or treatment of olfactory signals. Indeed, pups are very repulsive for a virgin female without experience and oestradiol may lower this repul- sion. It even seems that the physiological factors associated with parturition induce an attraction for the smell of the young [33], as has already been clearly determined in sheep [34].

In the ewe, the sensitive period is associated with a specific treatment of certain olfactory information. Thus, ewes are totally repelled by the smell of amniotic liquid at any moment of their reproductive cycle, except during a very short period around parturition during which the amniotic liquid becomes attractive [35]. This attraction, which depends on the cervico-vaginal stimulation caused by delivery, facilitates to establish the first contact of the mother with the newborn, its licking and its acceptation in general. The presence of the amniotic liquid is even essential in primiparous ewes (without previous maternal experience), who reject their newborn if it has been cleaned of all its amniotic liquid before being presented [34]. The sensitive period also represents a phase of very important olfactory learning for the ewe. Within the first 60 to $120 \mathrm{~min}$, she memorises the individual olfactory signature of her young; this smell then becomes the essential sensory signal that allows her to accept that her young nurse $[18,36]$. Here again, this learning is modulated by maternal physiological factors such as delivery of the foetus and the resulting liberation of some neurotransmitters. Finally, recent results indicate that the ease for this learning process by internal factors is probably not limited to olfaction, since recent results obtained in the ewe and goat have shown visual and/or auditory recognition in the young, 6 hours or less after parturition [36, 37].

\section{NEUROBIOLOGICAL MECHANISMS OF ACTIVATION OF MATERNAL BEHAVIOUR}

The neurobiological mechanisms implicated in the activation of maternal behaviour in mammals and the establishment of 
maternal selectivity in the ewe have been reported in various reviews [27, 38, 39]. They can be summarised as follows. In the female rat, the medial preoptic area (MPOA) is a structure essential for maternal activation. It is in particular the main area of action of oestrogens. In the nonmaternal female, the medial amygdala has an inhibiting action on the MPOA, under the influence of the olfactory system. This effect should be counteracted or even reversed at parturition in order to allow the expression of care to the young. The paraventricular nucleus (PVN) of the hypothalamus also plays an important role at parturition, being the source of intracerebral oxytocin secreted at this moment and facilitating the appearance of maternal behaviour by numerous projections and its diffusion in the cerebral ventricles [26, 38, 39].

In the ewe, the exact sites of oestradiol action remain to be determined. However, in a study where neurons that possess oestrogen receptors are marked, a particular expression of these neurons was shown several days before parturition in cerebral structures, whose implication is well established in the rat (MPOA, amygdala) or in ewes for oxytocin (PVN, medial amygdala). We also know that a release of noradrenalin, acetylcholine and oxytocin occurs at parturition in the olfactory bulbs and that these events are implicated in the memorisation of the odour of the lamb $[38,39]$. The existence of similar processes in the visual and auditory systems has not yet been verified.

\section{THE INFLUENCE OF EXPERIENCE ON THE MANIFESTATION OF MATERNAL BEHAVIOUR}

The capacity of the mother to show maternal behaviour towards her newborn is also influenced by experience. Of course, as we have already shown, this experience has shortterm effects since the experience acquired during the sensitive period influences the expression of maternal behaviour during the rest of lactation. However, the maternal experience acquired during the parental cycle may have long-term effects, for example on the appearance of care to young during the following cycles. Recent studies have even shown that the experience acquired in young rats during interaction with their mother can influence the expression of their maternal behaviour as an adult (non-genomic transgenerational effects).

The improvement of maternal behaviour between the first parturition and the following is well documented in the ewe. Maternal behavioural problems at parturition can be observed in primiparous ewes in proportions up to $50 \%$ or more. The most often, these troubles disappear within several hours and upon the second birth, the females all show well-adapted behaviour [40]. The comparison of mechanisms of control in primiparous and multiparous sheep indicate a larger aptitude to compensate for the absence of a controlling factor in experienced females than in females without maternal experience. For example, the suppression of the proprioceptive stimulation caused by delivery of the foetus has much more marked consequences in the primiparous ewe. The same is observed for the suppression of the olfactory information given by the newborn. The capacity of oestrogens to induce maternal behaviour is low in nulliparous ewes, not because oestradiol does not play a role but because in females without maternal experience, this factor alone is less efficient than that in experienced females. We thus observe an improvement of the compensation capacities between the different factors of control when one of them is absent with increasing parity. In other words, experience corresponds to an increase in the capacities of redundancy between the different factors [41].

In the female rat, the maternal behaviour shown at parturition varies little with experience $[5,20]$. However, its induction by the repeated presentation of the pups without 
any hormonal stimulation goes from 7 days in virgin rats to $24 \mathrm{~h}$ or less in multiparous rats. Several studies have established that the experience acquired by the interaction with the litter in the first hours following parturition plays a determining role in the acquisition of this "maternal memory". One hour of contact with pups at parturition is enough for a mother rat to again express maternal behaviour 10 days later in the absence of hormonal stimulation. The experiences acquired by virgin females during non hormonal sensitisation, or by the only "physiological" experience of gestation and of parturition are insufficient for the development of this maternal memory $[10,42$ 44].

The neurological mechanisms underlying this "maternal memory" associated with the first parental cycle have begun to be identified. Concerning the capacity of certain hormonal factors to activate maternal behaviour, several studies show that it probably depends in part on the more important expression of the corresponding receptors. In the mouse, we know that the expression of oestradiol receptors increases with maternal experience $[45,46]$. This is also the case in the ewe not only for oestrogen receptors in the structures such as MPOA and PVN [16], but also for oxytocin receptors [47]. In this species, there is also stronger liberation of certain neurotransmitters (noradrenalin, acetylcholine) in the olfactory bulbs in multiparous than in primiparous mothers, as well as a higher response to an oxytocin challenge [48, 49]. In the ewe, we do not currently know what is the part of the behavioural experience as compared to that of the "physiological" experience of gestation, parturition and first lactation and if as in the rat, the interaction between the psychological and physiological processes is determining, but it is noteworthy that certain modifications recorded at the physiological level can take place within a few hours. Also, in the rat, the studies of the research group of A Fleming in Canada have allowed to show that the accumbens nucleus plays an important role in the acquisition of long-term maternal memory [44].

Finally, studies developed by the groups of M. Meany and A. Fleming have shown inter-generational transmission of maternal influences in the expression of maternal behaviour. In the female rat, the early separation from the mother or the "quality of her maternal behaviour" can influence the development of the newborn and affect its future sensitivity to stress as well as the expression of its maternal behaviour, since these effects are transmitted from one generation to the next. The quality of the early environment, in particular the intensity of the licking behaviour of the mother, modulates the development of oestrogen and oxytocin receptors expression, in certain cerebral structures. A similar effect has also been identified for the non-genomic transmission of the sensitivity to stress [50-53].

\section{CONCLUSION}

This short review brings out the fact that parturition is associated with an increase of maternal motivation by internal physiological factors. Simultaneously, the processing of the sensory information coming from the newborn is modified at this moment, under the influence of internal maternal physiological factors. This has been found in all mammals studied up to now, including nonhuman primates and humans, at different degrees and even if the nature of the internal factors and sensory cues implicated varies between species. The capacity to show an adequate maternal behaviour is not only conditioned by genetic factor or purely physiological factors associated with parturition, but also depends on the individual experience of the subject. It is the combination of all of these parameters that allows to understand the existence of the more or less marked interindividual differences.

Finally, this review, like most that are available on physiological and sensory factors of control of the mother-young 
relationship, concerns the activation of maternal motivation. In fact, few studies exist on the mechanisms that ensure the maintenance and the extinction of maternal motivation. This is without doubt due to the major importance of the initial phase of maternal care for the survival of the newborn. This should not, however, mask the fact that from the beginning the relationship is not a one way process. A regulation of the behaviour of the mother by the young exists, which is an additional factor regulating maternal motivation, which would necessitate its own review. Some data show for example, that if we treat the young with certain drugs, the behaviour of the mother will change. In the same way, if we change the behaviour of the mother, by making her anosmic, it is the young animal that will change its strategy in order to nurse. There is really a dialogue that is established. This dialogue evolves over time and will eventually lead to the rupture of the bond between the mother and her young. Unlike the activation mechanisms, the processes that lead to the extinction of maternal motivation have been little studied, despite their interest to understand the control of natural weaning. To conclude, it is possible to understand the activation of maternal behaviour without taking the young into account, but one cannot ignore the offspring when studying the regulation of maternal motivation during lactation and weaning. Indeed, even if we know little on the subject, it is well established that the interactions with the young are essential to maintaining a high maternal motivation [54]. They can also control the progressive reduction of the time of contact and the length of nursing in species that build a nest [55].

\section{ACKNOWLEDGEMENTS}

I would like to thank the many people with whom I have collaborated in my research, in particular my colleagues at Nouzilly as well as Pierre Le Neindre that accompanied me in my first studies, and all my colleagues that collabo- rated with me in Australia and Mexico. Finally, I would like to acknowledge Charles Thibault for encouraging me and supporting my work at the beginning of my career, as well as JeanPierre Signoret and Georges Le Masne whose advice has been very precious.

\section{REFERENCES}

[1] González-Mariscal GP, Poindron P. Parental care in Mammals: Immediate internal and sensory factors of control. In: Pfaff DW, Arnold AP, Etgen AM, Fahrfbach SE, Rubin RT (Eds), Hormones, Brain and Behavior, Academic Press, New York 2002, p 215-298.

[2] Scafidi FA, Field TM, Schanberg SM, Bauer CR, Tucci K, Roberts J, C Morrow C, Kuhn $\mathrm{CM}$. Massage stimulates growth in preterm infants: A replication. Infant Behav Dev 1990, 13: 167-188.

[3] Kendrick KM, Hinton MR, Atkins K, Haupt MA, Skinner JD. Mothers determine sexual preferences. Nature 1998, 395: 229-230.

[4] Mirza SN, Provenza FD. Effects of age and conditions of exposure on maternally mediated food selection by lambs. Appl Anim Behav Sci 1992, 33: 35-42.

[5] Rosenblatt JS, Siegel HI, Mayer AD. Progress in the study of maternal behavior in the rat: hormonal, nonhormonal, sensory, and developmental aspects. Adv Study Behav 1979, 10: 225-311.

[6] Holmes WG. Parent-offspring recognition in mammals: a proximate and ultimate perspective. In: Krasnegor NA, Bridges RS (Eds), Mammalian Parenting: Biochemical, Neurobiological, and Behavioral Determinants, Oxford University Press, New-York. 1990, p 441-460.

[7] Poindron P, Schaal PB. Parent-infant relationships in Mammals: factors of control and psychobiological implications. In: Thibault C, Levasseur MC, Hunter RHF (Eds), Reproduction in Mammals and Man, Ellipses, 1993, p 553-565.

[8] Jensen P. Nest choice and nest-building of free-ranging domestic pigs due to farrow. Appl Anim Behav Sci 1989, 22: 13-21.

[9] Noirot E. The onset and development of maternal behavior in rats, hamsters and mice. Adv Study Behav 1972, 4: 107-145.

[10] Bridges RS. Endocrine regulation of parental behavior in Rodents. In: Krasnegor NA, 
Bridges RS (Eds), Mammalian Parenting: Biochemical, Neurobiological, and Behavioral Determinants, Oxford University Press, New-York, 1990, p 93-117.

[11] Rosenblatt JS, Siegel HI. Factors governing the onset and maintenance of maternal behavior among nonprimate Mammals. In: Gubernick DJ, Klopfer PH (Eds), Parental Care in Mammals, Plenum Press, New-York, 1981, p 13-76.

[12] Kennell JH. The human and health significance of parent-infant contact. J Am Osteopath Assoc 1987, 87: 638-645.

[13] Schaal PB, Porter BR. "Microsmatic Humans" revisited: The generation and perception of chemical signals. Adv Study Behav 1991, 20: 135-199.

[14] Kendrick KM, Keverne EB. Importance of progesterone and estrogen priming for the induction of maternal behavior by vaginocervical stimulation in sheep: effects of maternal experience. Physiol Behav 1991, 49: 745750.

[15] Poindron P, Lévy F, Krehbiel D. Genital, olfactory, and endocrine interactions in the development of maternal behaviour in the parturient ewe. Psychoneuroendocrinology 1988, 13: 99-125.

[16] Meurisse M, Gonzalez A, Delsol G, Caba M, Lévy F, Poindron P. Estradiol receptor- $\alpha$ expression in hypothalamic and limbic regions of ewes is influenced by physiological state and maternal experience. Horm Behav 2005, in press.

[17] Poindron P, Nowak R, Lévy F, Porter RH, Schaal PB. Development of exclusive motheryoung bonding in sheep and goats. Oxf Rev Reprod Biol 1993, 15: 311-364.

[18] Poindron P, Le Neindre P. Endocrine and sensory regulation of maternal behavior in the ewe. Adv Study Behav 1980, 11: 75-119.

[19] Lévy F, Gervais R, Kindermann U, Litterio M, Poindron P, Porter R. Effects of early postpartum separation on maintenance of maternal responsiveness and selectivity in parturient ewes. Appl Anim Behav Sci 1991, 31: 101-110.

[20] Rosenblatt JS, Lehrman DS. Maternal behavior in the laboratory rat. In: Rheingold HL (Ed), Maternal Behavior in Mammals, John Wiley \& Sons, Inc., New York, USA 1963, p 8-57.

[21] Bridges RS, Mann PE. Prolactin-brain interactions in the induction of material behavior in rats. Psychoneuroendocrinology 1994, 19: 611-622.

[22] Gonzalez-Mariscal G. Neuroendocrinology of maternal behavior in the rabbit. Horm Behav 2001, 40: 125-132.

[23] Yeo JA, Keverne EB. The importance of vaginal-cervical stimulation for maternal behaviour in the rat. Physiol Behav 1986, 37: 23-26.

[24] Bridges R. Biochemical basis of parental behavior in the rat. Adv Study Behav 1996, 25: 215-242.

[25] Mayer AD, Faris PL, Komisaruk BR, Rosenblatt JS. Opiate antagonism reduces placentophagia and pup cleaning by parturient rats. Pharmacol Biochem Behav 1985, 22: 1035-1044.

[26] González-Mariscal G, Melo AI, Chirino R, Jiménez P, Beyer C, Rosenblatt JS. Importance of mother/young contact at parturition and across lactation for the expression of maternal behavior in rabbits. Dev Psychobiol 1998, 32: 101-111.

[27] Numan M, Insel TR. The neurobiology of parental behavior. In: Ball GF, Balthazart J, Nelson RJ (Eds), Hormones, Brain and Behavior, Springer-Verlag, New York, p 418, 2003.

[28] Pryce CR. Socialization, hormones, and the regulation of maternal behavior in nonhuman primates. Adv Study Behav 1996, 25: 423 473.

[29] Maestripieri D, Zehr JL. Maternal responsiveness increases during pregnancy and after estrogen treatment in macaques. Horm Behav 1998, 34: 223-230.

[30] Maestripieri D. The biology of human parenting: insights from nonhuman primates. Neurosci Biobehav Rev 1999, 23: 411-422.

[31] Fleming AS, Ruble D, Krieger H, Wong PY. Hormonal and experiential correlates of maternal responsiveness during pregnancy and the puerperium in human mothers. Horm Behav 1997, 31: 145-158.

[32] Fleming AS, Corter C, Steiner M. Sensory and hormonal control of maternal behavior in rat and human mother. In: Martin RD, Pryce CR, Skuse D (Eds), Motherhood in human and nonhuman primates. Karger, 1995, 3rd SchultzBiegert Symposium, Kartause Ittingen.

[33] Fleming AS, Cheung U, Myhal N, Kessler Z. Effects of maternal hormones on "timidity" and attraction to pup-related odors in female rats. Physiol Behav 1989, 46: 440-453. 
[34] Lévy F, Keller M, Poindron P. Olfactory regulation of maternal behavior in mammals. Horm Behav 2004, 46: 284-302.

[35] Lévy F, Poindron P, Le Neindre P. Attraction and repulsion by amniotic fluids and their olfactory control in the ewe around parturition. Physiol Behav 1983, 31: 687-692.

[36] Keller M, Meurisse M, Poindron P, Nowak R, Ferreira G, Shayit M, Levy F. Maternal experience influences the establishment of visual/ auditory, but not olfactory recognition of the newborn lamb by ewes at parturition. Dev Psychobiol 2003, 43: 167-176.

[37] Poindron P, Gilling G, Hernandez H, Serafin N, Terrazas A. Early recognition of newborn goat kids by their mother: I. Nonolfactory discrimination. Dev Psychobiol 2003, 43: 82-89.

[38] Kendrick KM. Oxytocin, motherhood and bonding. Exp Physiol 2000, 85: 111-124.

[39] Lévy F, Kendrick K, Keverne EB, Porter RH, Romeyer A. Physiological, sensory and experiential factors of parental care in sheep. Adv Study Behav 1996, 25: 385-473.

[40] Poindron P, Raksanyi I, Orgeur P, Le Neindre P. Comparaison du comportement maternel en bergerie à la parturition chez des brebis primipares ou multipares de race Romanov, Préalpes de Sud et Ille-de-France. Génét Sél Évol 1984, 16: 503-522.

[41] Poindron P, Lévy F. Physiological, sensory and experiential determinants of maternal behaviour in sheep. In: Krasnegor NA, Bridges RB (Eds), Mammalian Parenting: Biochemical, Neurobiological and Behavioral Determinants, Oxford University Press, New-York 1990, p 133-156.

[42] Bridges RS. Retention of rapid onset of maternal behavior during pregnancy in primiparous rats. Behav Biol 1978, 24: 113-117.

[43] Orpen BG, Fleming AS. Experience with pups sustains maternal responding in postpartum rats. Physiol Behav 1987, 40: 47-54.

[44] Lee A, Li M, Watchus J, Fleming AS. Neuroanatomical basis of maternal memory in postpartum rats: selective role for the nucleus accumbens. Behav Neurosci 1999, 113: 523538.

[45] Koch M. Effects of treatment with estradiol and parental experience on the number and distribution of estrogen-binding neurons in the ovariectomized mouse brain. Neuroendocrinology 1990, 51: 505-514.

[46] Ehret G, Buckenmaier J. Estrogen-receptor occurrence in the female mouse brain: Effects of maternal experience, ovariectomy, estrogen and anosmia. J Physiol (Paris) 1994, 88: 315-329.

[47] Broad KD, Lévy F, Evans G, Kimura T, Keverne EB, Kendrick KM. Previous maternal experience potentiates the effect of parturition on oxytocin receptor mRNA expression in the paraventricular nucleus. Eur J Neurosci 1999, 11: 3725-3737.

[48] Lévy F, Guevara-Guzman R, Hinton MR, Kendrick KM, Keverne EB. Effects of parturition and maternal experience on noradrenaline and acetylcholine release in the olfactory bulb of sheep. Behav Neurosci 1993, 107: 662-668.

[49] Lévy F, Kendrick KM, Goode JA, GuevaraGuzman R, Keverne EB. Oxytocin and vasopressin release in the olfactory bulb of parturient ewes: changes with maternal experience and effects on acetylcholine, gamma-aminobutyric acid, glutamate and noradrenaline release. Brain Res 1995, 669: 197-206.

[50] Meaney MJ. Maternal care, gene expression, and the transmission of individual differences in stress reactivity across generations. Annu Rev Neurosci 2001, 24: 1161-1192.

[51] Champagne F, Diorio J, Sharma S, Meaney MJ. Naturally occurring variations in maternal behavior in the rat are associated with differences in estrogen-inducible central oxytocin receptors. Proc Natl Acad Sci USA 2001, 98: 12736-12741.

[52] Breton C, Pechoux C, Morel G, Zingg HH Oxytocin receptor messenger ribonucleic acid: characterization, regulation, and cellular localization in the rat pituitary gland. Endocrinology 1995, 136: 2928-2936.

[53] Gonzalez A, Lovic V, Ward GR, Wainwright $\mathrm{PE}$, Fleming AS. Intergenerational effects of complete maternal deprivation and replacement stimulation on maternal behavior and emotionality in female rats. Dev Psychobiol 2001, 38: 11-32.

[54] Grosvenor C, Mena EF. Neural and hormonal control of milk secretion and milk ejection. In: Larson BL, Smith VR (Eds), Lactation: A Comprehensive Treatise, Academic Press, New York, 1974, p 227-276.

[55] Leon M, Coopersmith R, Beasley LJ, Sullivan RM. Thermal aspects of parenting. In: Krasnegor NA, Bridges RS (Eds), Mammalian Parenting: Biochemical, Neurobiological, and Behavioral Determinant, Oxford University Press, NewYork, 1990, p 400-415. 